\title{
REFLEXÕES SOBRE ENSINO DE BIBLIOTECONOMIA: ênfase curricular na função educacional do serviço de referência e da competência em informação
}

\author{
MARTA LEANDRO DA MATA* \\ MERI NADIA MARQUES GERLIN*
}

\begin{abstract}
RESUMO
O presente artigo pretende trazer à reflexão o percurso do ensino de Biblioteconomia no Brasil desde o estabelecimento da profissão com seu primeiro currículo mínimo até as Diretrizes Curriculares Nacionais, com ênfase curricular na formação de usuários, ao destacar a oferta de disciplinas sobre o Serviço de Referência, Educação de Usuários e Competência em Informação. Por meio de um levantamento teórico, no âmbito da Biblioteconomia e da Ciência da Informação, identificou-se que os bibliotecários, além de trabalharem com as atividades de organização e tratamento da informação nas unidades de informação, também devem dedicar-se aos serviços voltados aos usuários, por exemplo, na orientação no serviço de referência, na implementação de programas de competência em informação nas instituições de ensino, já que estes profissionais possuem um papel fundamental em relação aos processos educativos do universo informacional, contribuindo para o processo de ensino-aprendizagem dos indivíduos.
\end{abstract}

PALAVRAS-CHAVE: Biblioteconomia. Serviço de Referência. Educação de Usuários. Formação de Usuários. Competência em Informação.

\begin{abstract}
In view of this, this article intends to reflect on the course of the teaching of Librarianship in Brazil from the establishment of the profession with its first minimal curriculum to the National Curricular Guidelines, with curricular emphasis in the training of users, that is, from the offering of disciplines Reference Service, User Education and Information Competence. Through a theoretical survey, in the scope of Librarianship and Information Science, it was identified that librarians, in addition to working with information organization and treatment activities in information units, should also dedicate
\end{abstract}

\footnotetext{
Professora do Departamento de Biblioteconomia. Doutora em Ciência da Informação (UFES)

** Doutora em Ciencias da Informação, Dinter UnB/UFES.
} 
themselves to services aimed at users, for example, in the implementation of programs of competence in information in educational institutions, since these professionals have a fundamental role in relation to the educational processes of the informational universe, contributing to the teaching-learning process of individuals.

KEYWORD: Library Science. Reference Service. User Training. User Education. Information Literacy.

\section{INTRODUÇÃO}

As ações associadas à competência em informação realizadas por bibliotecários podem contribuir significativamente com o processo de construção do saber dos indivíduos durante sua formação escolar/acadêmica, com ênfase no desenvolvimento de conhecimentos (saber ser), habilidades (saber fazer) e atitudes (saber agir) referentes ao manuseio do universo informacional.

Os profissionais bibliotecários devem atuar tendo em vista sua responsabilidade social, visando a cooperar com a formação de cidadãos conscientes de seus direitos e deveres. De acordo com Freire (2006, p. 228), "[...] um dos objetivos da Ciência da Informação seria o de contribuir para a informação se tornar, cada vez mais, um elemento de inclusão social, oferecendo oportunidades de inclusão para pessoas, grupos e nações". A partir de estudos teóricos, práticos e metodológicos sobre a competência em informação, a Biblioteconomia e a Ciência da Informação evidenciam os aspectos sociais e educacionais da área.

Observa-se que os bibliotecários além de trabalharem com as atividades de organização e tratamento da informação nas unidades de informação, que são próprias da profissão, devem dedicar-se aos serviços voltados para a implementação de programas de competência em informação nas instituições de ensino, já que estes profissionais possuem um papel fundamental em relação ao ensino acerca do universo informacional e de seus processos, contribuindo para o processo de ensino-aprendizagem dos indivíduos.

Compreende-se que as disciplinas de formação específica são o núcleo base da profissão e fundamentais para a formação e atuação do bibliotecário. Essas disciplinas se encontram em grandes áreas estabelecidas pela Associação Brasileira e Educação em Ciência da Informação (ABECIN), a saber: Fundamentos Teóricos da Biblioteconomia, Ciência da Informação e áreas afins; Organização e Tratamento da Informação; Recursos e Serviços de Informação; Gestão de Unidades de Informação; Tecnologia da Informação. 
O domínio das competências específicas da profissão possibilita ao bibliotecário desenvolver sua própria competência em informação, exercer as atividades de organização e tratamento da informação e, a partir disso, ter os conhecimentos necessários para ensinar outras pessoas acerca do funcionamento do universo informacional no que condiz à organização e aos processos informacionais.

O curso de Biblioteconomia também é constituído de disciplinas de formação humanística, como de história, sociologia, filosofia, visando a possibilitar o entendimento das dimensões sociais, políticas e culturais do ambiente em que está inserido, a fim de que ultrapasse os aspectos utilitários imediatos de determinados contextos históricos, conforme sugerido pelo Ministério da Educação (MEC) (BRASIL, 2001). Estas disciplinas possibilitam aos graduandos desenvolverem uma visão crítica quanto à organização social e à sua estrutura, tendo-se uma percepção do macro e do micro ambientes.

A área de formação voltada para os recursos e serviços de informação visa estabelecer a mediação da informação entre o usuário e as fontes de informação, no que se refere ao planejamento dos sistemas e canais de disseminação da informação. Essa área é composta por disciplinas de fontes de informação, serviço de referência e informação, estudo de usuários, mediação da informação, educação de usuários e competência em informação, entre outras.

Assim sendo, algumas questões sobre a formação deste profissional devem ser objeto de reflexão: será que os cursos de Biblioteconomia têm adotado em suas matrizes curriculares conteúdos que contemplem o desenvolvimento de sua função educacional? Enfatizando-se, desse modo, desde o serviço de referência à competência em informação?

O presente artigo pretende trazer à reflexão o percurso do ensino de Biblioteconomia no Brasil desde o estabelecimento da profissão com seu primeiro currículo mínimo até as Diretrizes Curriculares Nacionais (DCN), perpassando pelos relatórios dos Encontros de diretores e de docentes de escolas de Biblioteconomia e Ciência da Informação do Mercado Comum do Sul (MERCOSUL). Posteriormente, traça a relação do serviço de referência e da competência em informação. Para tanto, realizou-se um levantamento teórico sobre aspectos relacionados com o currículo do Curso de Biblioteconomia. 


\section{O ENSINO DE BIBLIOTECONOMIA: DO CURRÍCULO MÍNIMO ÀS DIRETRIZES CURRICULARES NACIONAIS}

Na década de 1960 a Lei 4.084, de 30 de junho de 1962 que dispõe acerca da profissão de bibliotecário e regulamenta seu exercício foi estabelecida, bem como o primeiro currículo mínimo de Biblioteconomia instituído pelo Conselho Federal de Educação pela Resolução de 16 de novembro de 1962. O currículo mínimo passou a ser obrigatório aos cursos a partir de 1963 prevendo a duração de três anos letivos sendo composto pelas seguintes disciplinas:

- História do Livro e das Bibliotecas;

- História da Literatura;

- História da Arte;

- Introdução aos Estudos Históricos e Sociais;

- Evolução do Pensamento Filosófico e Científico;

- Organização e Administração de Bibliotecas;

- Catalogação e Classificação;

- Bibliografia e Referência;

- Documentação;

- Paleografia (LEMOS, 1973).

Com o reconhecimento do curso de nível superior e com o estabelecimento de um currículo mínimo, foi possível obter maior uniformização no ensino da Biblioteconomia e uma formação cultural mais diversificada do bibliotecário. As escolas poderiam acrescentar outras disciplinas, de modo a formar o currículo pleno ${ }^{1}$, todavia, a maioria manteve apenas a estrutura curricular mínima exigida. A justificativa seria devido à carência de pessoal docente e à percepção deficiente de todo o espectro de conhecimentos específicos que a Biblioteconomia envolvia (LEMOS, 1973).

A questão da carga horária de 2.025 horas de atividades didáticas, medida de cunho normativo promovida pelo Ministério da Educação, ocasionou um superdimensionamento do conteúdo das disciplinas de ordem técnica, com o intuito de preencher o tempo disponível na maioria dos cursos (LEMOS, 1973). Dessa forma, aumentou a lacuna em relação às disciplinas de cunho social e político, isto é, humanísticas que deveriam oferecer aos formandos uma visão mais ampla da realidade que vivenciam.

\footnotetext{
${ }^{1}$ Por meio do currículo pleno desenvolve-se "[...] a adaptação do currículo mínimo às peculiaridades de cada escola de biblioteconomia, levando em consideração seu contexto social, as peculiaridades regionais e o perfil do profissional almejado." (GUIMARÃES, 2002, p. 51)
} 
Apesar dos diversos problemas encontrados a aprovação deste primeiro currículo mínimo e a regulamentação da profissão foram grandes conquistas, cujos resultados foram fruto da junção de movimentos profissionais e escolas de Biblioteconomia que ocorreram a partir de eventos da área, como o Congresso Brasileiro de Biblioteconomia e Documentação (CBBD).

Conforme expõe Mota e Oliveira (2008), no período entre 1950 a 1960 surgiram fortes entidades de classes, como a Federação Brasileira de Associações de Bibliotecários (FEBAB ${ }^{2}$ ) fundada em 1959, o Conselho Federal de Biblioteconomia (CFB) em 1966 (mesmo ano em que é aprovado o primeiro código de ética da área) e a Associação Brasileira de Ensino de Biblioteconomia e Documentação (ABEBD) em 1967. Esta última desempenhando um papel essencial, promovendo reuniões entre professores de disciplinas afins de várias escolas (MUELLER, 1985; MOTA; OLIVEIRA, 2008).

Em 1960 foi criada uma disciplina curricular denominada "Bibliografia e Referência", com conteúdos voltados para o serviço, processo e entrevista de referência, técnica de disseminação da informação e formação de usuários. Essa disciplina possibilitava a aquisição de conhecimentos para que o bibliotecário interagisse com os usuários visando compreender e satisfazer suas necessidades informacionais, bem como com planejamento de atividades visando auxiliá-los no uso do sistema de informação, seus recursos e produtos.

Destaca-se o primeiro programa de orientação bibliográfica, implantado em 1955 pela bibliotecária Terezine Arantes Ferraz da Universidade de São Paulo (USP), levando o nome de Pesquisa Bibliográfica. Depois disso, houve outras iniciativas em diferentes áreas e instituições, como o oferecimento de disciplinas específicas de Orientação Bibliográfica aos usuários de informação. Ocorreu ainda a criação de manuais específicos e a divulgação dos relatos de experiências através de periódicos da área. Ressalta-se que estas iniciativas estiveram voltadas para instituições do ensino superior (BELLUZZO, 1989). A criação deste programa pode ter causado impacto na ementa das disciplinas de serviço de referência daquela época.

A década de 1970 foi marcada pela instabilidade política e por um acentuado crescimento econômico, impulsionando o desenvolvimento do ensino superior e do campo científico devido à criação dos cursos de pós-graduação stricto sensu e latu sensu em

\footnotetext{
${ }^{2}$ Atualmente, designada como Federação Brasileira de Associações de Bibliotecários, Cientistas da Informação e Instituições.
} 
vários ramos do conhecimento, inclusive na Biblioteconomia, dando início aos cursos de mestrado. De acordo com Ota (1990, p. 61), "[...] iniciou-se a produção técnico-científica na área, surgindo quatro revistas especializadas. O número de trabalhos publicados em congressos e artigos tendeu a aumentar".

As associações profissionais mostraram-se fortes e consolidadas, realizaram muitas reuniões organizadas pela Associação Brasileira das Escolas de Biblioteconomia e Documentação, o que incentivou o fortalecimento de discussões no que concerne às questões curriculares entre professores de áreas afins, muitas delas ocorrendo concomitantemente com ao CBBD. A primeira foi um encontro de professores em Belo Horizonte, com a colaboração da Escola de Biblioteconomia da Universidade Federal de Minas Gerais (UFMG), que visava debater este primeiro currículo mínimo. As questões curriculares na área encontram-se ligadas à trajetória desta associação (GUIMARÃES, 2002).

Em 1981 um Grupo de Trabalho liderado pela presidente da ABEBD, com a participação de professores UFMG, USP, Universidade Federal de Pernambuco (UFPB), Universidade Federal do Paraná (UFPR), Universidade de Brasília (UNB) e Instituto Brasileiro de Informação em Ciência e Tecnologia (IBICT) e assessores técnicos da Secretaria de Ensino Superior (SESU) do MEC, apresentou uma proposta da reformulação do currículo mínimo em Biblioteconomia (CARVALHO, 1985 apud GUIMARÃES, 2002).

Em 1982, um novo currículo mínimo é aprovado, através da publicação do Conselho Federal de Educação, por meio da Resolução $n^{\circ}$ 08/82 fixando os mínimos de conteúdo e duração do curso de Biblioteconomia, trazendo novas alterações curriculares, bem como um período mais amplo de duração do curso com cerca de quatro anos (totalizando uma carga horária mínima de 2.500 horas). As matérias foram divididas em três linhas (OLIVEIRA; CARVALHO; SOUZA, 2009):

\section{Matérias de fundamentação geral}

1. Comunicação;

2. Aspectos sociais, políticos e econômicos do Brasil contemporâneo;

3. História da Cultura.

\section{Matérias instrumentais}

1. Lógica;

2. Língua portuguesa e literatura da língua portuguesa;

3. Língua estrangeira e moderna;

4. Métodos e técnicas de pesquisa. 


\section{Matérias de formação profissional}

1. Informação aplicada à Biblioteconomia;

2. Produção dos registros do conhecimento;

3. Formação e desenvolvimento de coleções;

4. Controle bibliográfico dos registros do conhecimento;

5. Disseminação da informação;

6. Administração de bibliotecas.

Quanto à estrutura curricular, Guimarães (2002) expõe que ocorreu uma distinção entre matérias de conteúdo específico (formação profissional) e outras com função-base (instrumentais e de fundamentação geral). Souza (2011) aponta que foram inseridas disciplinas da área de administração, de psicologia, de antropologia e de metodologia da pesquisa, retirando a centralidade em torno da catalogação e da classificação. Entretanto, houve a saída de uma disciplina instrumental, a "Evolução do pensamento científico e filosófico", que foi considerada uma grande perda para a área. Por outro lado, ganhou-se a disciplina de "Lógica", também importante, mas com enfoque distinto.

Mueller (1985, p. 13) observa que a literatura profissional vinha "[...] conclamando a classe para se reconhecer como um agente social preocupado com o acesso do povo à informação, à educação e à cultura, com responsabilidades no desenvolvimento da ciência e da técnica, e em todos aspectos da vida nacional e individual [...]".

Durante esse período houve um considerável aumento dos encontros realizados pela área por meio do CBBD, abarcando temas mais especializados. Alguns de caráter regional, no entanto, com maior tentativa de convivência entre profissionais e propiciando a troca de conhecimentos e discussões na área (OLIVEIRA; CARVALHO; SOUZA, 2009).

No segundo currículo mínimo, no que tange às disciplinas voltadas para a prestação de serviços aos usuários, ocorreu a exclusão de uma disciplina com a nomenclatura "Referência", ao mesmo tempo em que houve a inserção de uma denominada "Disseminação da Informação". Essa disciplina contemplava conteúdos referentes ao serviço de referência e informação, bem como aos produtos e serviços de disseminação da informação. A título de exemplo, pode-se mencionar a ementa da disciplina "Disseminação da Informação" do curso de Biblioteconomia da Universidade Estadual Paulista (UNESP), que permaneceu com esta terminologia até os dias de hoje, a saber: "Conceitos e espaços 
da disseminação da informação. O serviço de referência e informação em unidades de informação: conceitos, estruturas e ações." (UNIVERSIDADE..., 2012).

Naquela época, Macedo (1987) realizou uma pesquisa sobre a distribuição de dissertações em teses em Ciência da Informação e Biblioteconomia por grandes e pequenos assuntos, entre o período de 1973 e 1985. Forma analisadas 279 teses e dissertações em Ciência da Informação, sendo que somente quatro eram sobre educação de usuários e uma sobre o Serviço de Referência. Observa-se um número reduzido de trabalhos voltados para estas temáticas naquele período, entretanto, ressalta-se que os temas começam a ganhar destaque e importância a partir desta década no contexto brasileiro.

$\mathrm{Na}$ década de 1990 houve uma série de discussões problematizadas devido às rápidas transformações que ocorriam, centrando-se no advento das tecnologias de informação e comunicação, na mudança do paradigma do acervo para a informação (VALENTIM, 1995), assim como no que se relaciona à globalização da economia que movimentava vários segmentos de mercado.

Com base nestes fatores, as discussões predominantes na área foram sobre as possíveis mudanças nos fazeres bibliotecários e a ampliação dos seus locais de atuação, iniciando-se uma busca por tentar definir o seu perfil profissional. Compreende-se que é importante atentar-se às mudanças sociais e às suas consequências no mercado de trabalho, porém, o perfil do profissional não deve ser elaborado somente com base neste aspecto.

A ABEBD, por sua vez, organizou grupos regionais para tratar da discussão sobre o perfil destes profissionais, no que tange a competência, habilidades e conhecimentos, levando em consideração sua localização geográfica. Essa associação fazia parte do programa do II Plano para o Desenvolvimento Educativo Regional dos países do MERCOSUL, levando a realização do Encontro de Dirigentes de Escolas Universitárias de Biblioteconomia do MERCOSUL, com uma proposta de harmonização curricular de tais cursos (GUIMARÃES, 2002).

No mesmo momento, surge uma nova denominação para o bibliotecário, "Moderno Profissional da Informação" (MIP), conforme atribuído pela Federação Internacional de Informação e Documentação (FID). No contexto brasileiro, foi trazida pela ABEBD, seguida de vários artigos de Santos (1996), Guimarães (1997), Valentim (2000) e outros profissionais. De acordo com Souza (2009), "[...] se instalou um debate que se estendeu até o fim da 
década, identificando-se e contrastando os prós e contras da adoção de uma nova designação profissional".

Nessa década, também se constitui uma nova regulamentação da Lei de Diretrizes e Bases da Educação Nacional (LDB), com a Lei $n^{\circ}$ 9.394, de 20 de dezembro de 1996 (BRASIL, 1996). Segundo Guimarães (2002, p. 62) essas diretrizes enunciavam uma "[...] concepção de ensino baseado em princípios como a flexibilidade curricular, integração graduação/pós-graduação, integração universidade/comunidade, desenvolvimento de projetos políticos pedagógicos como base para a ação educativa e avaliação global do processo formativo".

Entre as mudanças, propunha-se a substituição do currículo mínimo por diretrizes curriculares que visavam a orientar os cursos de nível superior, culminado em uma nova discussão para a elaboração do currículo. Por sua vez, em 2001, foram publicadas essas novas diretrizes (BRASIL, 2001) com o objetivo de orientar a formulação do projeto pedagógico do curso, que deveria ser constituído pelos seguintes itens: perfil dos formandos, competências e habilidades, conteúdos curriculares, estágios e atividades complementares, estrutura do curso e avaliação institucional. De acordo com Castro (2002, p. 26):

[...] os princípios que norteiam as propostas das Diretrizes Curriculares são a flexibilização na organização dos cursos e a consciência da diversidade/heterogeneidade do conhecimento do aluno, no que se refere tanto à sua formação anterior, quanto aos seus interesses e expectativas em relação aos atuais e futuros exercícios da profissão.

Essas diretrizes ofereceram às Escolas maior flexibilidade na elaboração de um novo currículo para o curso, contemplando mais as necessidades regionais e as características contextuais de suas instituições, oferecendo maior ênfase ao aluno. Esse aspecto pode ser observado no tópico referente à estrutura do curso, que "[...] deverá ser definida pelo respectivo colegiado, que indicará a modalidades de seriação, de sistema de créditos ou modular." (BRASIL, 2001).

Na visão de Souza (2002), a partir do DCN, foi superada a organização do currículo centrado em grades disciplinares, substituídas por orientações globais com vários componentes que articulam os projetos educacionais voltados para a formação do bibliotecário. Desta forma, o currículo de cada escola passa a ser 
encargo da própria instituição, da responsabilidade social e política da categoria profissional supramencionada.

O perfil profissional, muito discutido na década anterior, foi proposto por meio das DCN (BRASIL, 2001, p. 32), com enfoque em uma formação a partir de competências e habilidades, em diversos locais de atuação:

A formação do bibliotecário supõe o desenvolvimento de determinadas competências e habilidades e o domínio dos conteúdos da Biblioteconomia. [...] os egressos dos referidos cursos deverão ser capazes de atuar junto a instituições e serviços que demandem intervenções de natureza e alcance variados: bibliotecas, centros de documentação ou informação, centros culturais, serviços ou redes de informação, órgãos de gestão do patrimônio cultural etc.

Quanto à atribuição de determinadas competências e habilidades, essas foram distribuídas entre gerais e específicas, a saber:

\section{A) Gerais}

- gerar produtos a partir dos conhecimentos adquiridos e divulgá-los;

- formular e executar políticas institucionais;

- elaborar, coordenar, executar e avaliar planos, programas e projetos;

- utilizar racionalmente os recursos disponíveis;

- desenvolver e utilizar novas tecnologias;

- traduzir as necessidades de indivíduos, grupos e comunidades nas respectivas áreas de atuação;

- desenvolver atividades profissionais autônomas, de modo a orientar, dirigir, assessorar, prestar consultoria, realizar perícias e emitir laudos técnicos e pareceres;

- responder a demandas sociais de informação produzidas pelas transformações tecnológicas que caracterizam o mundo contemporâneo.

\section{B) Específicas}

- Interagir e agregar valor aos processos de geração, transferência e uso da informação em todo e qualquer ambiente;

- Criticar, investigar, propor, planejar, executar e avaliar recursos e produtos de informação;

- Trabalhar com fontes de informação de qualquer natureza; 
- Processar a informação registrada em diferentes tipos de suporte mediante a aplicação de conhecimentos teóricos e práticos de coleta, processamento, armazenamento e difusão da informação;

- Realizar pesquisas relativas a produtos, processamento, transferência e uso da informação.

Com relação aos conteúdos curriculares, aponta-se nas DCN que os cursos devem distribuir suas disciplinas entre conteúdos de formação geral e formação específica. Neste sentido, é importante dar ênfase a recomendação do MEC: "[...] os projetos acadêmicos acentuem a adoção de uma perspectiva humanística na formulação dos conteúdos, conferindo-Ihes um sentido social e cultural que ultrapasse os aspectos utilitários mais imediatos sugeridos por determinados itens" (BRASIL, 2001, p. 33).

Compreende-se, assim, que deve haver maior diálogo da área com conteúdos interdisciplinares, permitindo a obtenção de uma formação com mais densidade humanística, o que propicia ao formando uma visão mais crítica da sociedade e do meio em que está inserido, com capacidade de análise da própria profissão e das instituições em que atua.

Destaca-se que, durante este período, houve debates acerca das novas formas de armazenamento da informação versus o papel, no que concerne às bibliotecas digitais e virtuais, do crescimento vertiginoso das informações, da difusão e compartilhamento de uma grande quantidade de informações na web social. Em relação à formação educacional, em diversos países, o sistema de ensino está centrado em competências.

A partir da flexibilização propiciada pelas DCN outras disciplinas foram inseridas nos cursos. Um documento complementar foi publicado em 2010, os "Referenciais Curriculares Nacionais dos Cursos de Bacharelado e Licenciatura" pelo Ministério da Educação (MEC). Nesta obra são sugeridos os assuntos que devem ser abordados nos cursos de graduação, inclusive de Biblioteconomia. Este documento aponta a inserção de conteúdos sobre "[...] Serviços de Referência; Comunicação; Formação de Leitores; Competência em Informação [...]" (BRASIL, 2010, p. 9, grifo nosso).

Em documentos resultantes dos "Encontros de Diretores e Docentes de Escolas de Biblioteconomia e Ciência da Informação do MERCOSUL", desde 2000, é possível encontrar menções à formação de usuários na área de Recursos e Serviços de 
Informação, especificamente, nas recomendações de conteúdos que devem ser abarcados em suas "Linhas de Investigação" (BARITÉROQUETA, 2014), bem como nas "Articulações da pesquisa com o Ensino e Extensão" (VALENTIM, 2014).

No encontro realizado em 2001, no que se refere às inovações propostas em estratégias de ensino, aponta-se como uma das perspectivas "Revalorizar o seu rol de produtos de informação com valor agregado, centrado nas necessidades, interesses e comportamentos dos usuários." (ESCOBAR-DE-MOREL, 2014, p. 100). Assim, compreende-se a realização de estudos de usuários visando a criação de serviços especializados para atender suas necessidades informacionais, englobando ações educacionais sobre o sistema de informação e seus produtos e recursos.

Em evento realizado em 2012, no Uruguai, enfatizam-se as principais linhas de pesquisa desta área, com os seguintes temas: Estudo de Usuários; Desenvolvimento de coleções de novos ambientes; Alfabetização informacional na Sociedade do Conhecimento; Produção de conteúdos; Acesso à informação pública; Comportamentos de produção científica; Biblioterapia; Práticas de leitura; Repositórios institucionais. Destaca-se que há uma mudança no termo utilizado para designar o desenvolvimento de programas educacionais em bibliotecas, com a alfabetização em informação (VALENTIM, 2014).

No relatório do " $X$ Encontro de docentes de escolas de Biblioteconomia e Ciência da Informação do MERCOSUL", recomendou-se "Discutir o espaço na ementa referente a área de Competência em Informação, encaminhando o diálogo no próximo encontro" (ASSOCIAÇÃO..., 2016).

Em 2014, Mata (2014) identificou disciplinas que contemplavam conteúdos curriculares sobre competência em informação nos cursos de Biblioteconomia do Brasil. Os resultados mostraram que dos 39 cursos existentes, 10 possuíam disciplinas sobre competência em informação ou equivalentes ${ }^{3}$, sendo que sete eram obrigatórias e três eram optativas. Três cursos continham disciplinas de educação de usuários, todas de caráter obrigatório, contudo, na bibliografia básica e complementar dos planos de ensino, duas delas possuem diversas obras em comum referentes à competência em informação.

Foram analisadas outras disciplinas que pudessem abordar a competência em informação nos currículos dos cursos de

\footnotetext{
${ }^{3}$ As disciplinas encontradas nos currículos eram denominadas de competência em informação, competência informacional, letramento informacional e infoeducação.
} 
Biblioteconomia, com ênfase na área de recursos e serviços informacionais. Após análise do plano de ensino das disciplinas de "estudo de usuários", constatou-se que o termo "Competência Informacional" foi citado em dois, bem como na disciplina de "Serviço de Referência", que também foi mencionado em dois planos de ensino.

De modo geral, percebem-se na trajetória curricular do curso de Biblioteconomia do Brasil disciplinas que contemplem a formação de usuários em seu amplo aspecto. Inicialmente, com as disciplinas voltadas para o Serviço de Referência nos currículos mínimos, considerando-se que seu conteúdo está voltado às funções de: acolher (receptividade em relação aos usuários), informar (resolver as perguntas e as pesquisas dos usuários), formar (ensiná-los na utilização dos serviços e recursos da biblioteca) e orientar (orientação física e bibliográfica) (MANGAS, 2007). Estas últimas funções englobam as ações de formação de usuários.

Em um segundo momento, a partir da introdução das Diretrizes Curriculares Nacionais de Biblioteconomia (2001), percebe uma flexibilização dos seus conteúdos curriculares estruturantes, com destaque para a seguinte competência e habilidade geral: "elaborar, coordenar, executar e avaliar planos, programas e projetos". No que se refere às específicas, destacamse: "Criticar, investigar, propor, planejar, executar e avaliar recursos e produtos de informação; e Trabalhar com fontes de informação de qualquer natureza". Essas competências e habilidades possibilitam aos graduandos de Biblioteconomia obter conhecimento para oferecem serviços e recursos informacionais.

Neste âmbito, também foi possível perceber uma preocupação em documentos dos encontros de docentes e diretores dos cursos de Biblioteconomia do MERCOSUL, mencionando-se como linhas de investigação e de ensino a formação de usuários. Atualmente, designada competência em informação, abrangendo atividades educacionais voltadas para o universo informacional e seus processos de busca, avaliação, uso e comunicação da informação de modo ético, visando o desenvolvimento de habilidades informacionais nos usuários.

Ressaltam-se também as investigações no âmbito da PósGraduação em Biblioteconomia e Ciência da Informação com temas sobre a Educação de usuários e Serviço de Referência a partir da década de 1980 (MACEDO, 1987). Atualmente, em pesquisa realizada por Leite et al. (2016), tendo-se como corpus os documentos divulgados nas edições do Encontro Nacional de 
Pesquisa e Pós-Graduação em Ciência da Informação (ENANCIB), no período de 1994 a 2015, sobre a literatura produzida em Competência em Informação, verificou-se um total de 72 trabalhos acerca da temática. Esses resultados influenciam fortemente nos temas e conteúdos disciplinares dos cursos de Biblioteconomia, visto serem produções advindas do principal evento científico na área no Brasil, promovido pela Associação Nacional de Pesquisa e Pós-Graduação em Ciência da Informação (ANCIB).

A seguir apresenta-se uma contextualização acerca da conexão de conceitos que giram em torno do serviço de referência e da competência em informação, ao referenciar um moderno profissional da informação que adquire saberes $e$ fazeres proporcionados por um currículo em permanente constituição.

\section{O INTERCAMBIAMENTO DE CONCEITOS EM TORNO DO SERVIÇO DE REFERÊNCIA E DA COMPETÊNCIA EM INFORMAÇÃO}

Nóbrega (1995, p. 7) permite refletir que em um contexto de busca e de recuperação da informação as recordações podem constantemente ser alarmadas pelas "Lombadas milimetricamente etiquetadas, num virar de costas para o leitor, escondendo as entranhas do acervo, seu verdadeiro tesouro". Essa colocação relacionada aos contextos de atendimentos presenciais devidamente reconhecidos por um currículo mínimo pode ser estendida para os ambientes virtuais de compartilhamento da informação na contemporaneidade.

O currículo do Curso de Biblioteconomia deve oferecer estrutura para que no mercado de trabalho o profissional bibliotecário adquira conhecimentos e habilidades, de forma a oferecer ao usuário inúmeras possibilidades de acesso aos fluxos informacionais, tesouros escondidos em um labirinto hipertextual proporcionado pela sociedade da informação. $\mathrm{Na}$ atualidade falta competência tanto ao profissional de referência quanto ao usuário, impedindo-os, muitas vezes, de ressignificar os tradicionais contextos de busca, seleção e acesso à informação, importantes para ocasionar no seu uso efetivo e na sua aplicação no contexto social.

O serviço de auxílio ao usuário não foi sempre parte integrante da Biblioteconomia conforme levantado por Grogan (2007). A utilização do termo "referência" data de 1820, aparecendo como uma tradução do inglês "reference" ao fazer referência a uma 
obra no sentido pleno da palavra ou ao ato de se dirigir a alguém para obter informações (ACCART, 2012).

A essência do serviço de referência como auxílio ao leitor foi citada em 1876 durante a "Centennial Conference of Librarians" na Filadelfia (EUA) ${ }^{4}$, sendo nela mencionado por Samuel Swett Green a relevância do auxílio aos leitores em relação ao uso da coleção, a função educativa da biblioteca e a emancipação do profissional da informação inserido nos novos padrões do conhecimento. Por volta de 1888 Melvil Dewey empregava a denominação bibliotecário de referência, todavia, essa função não era totalmente aceita, o que veio acontecer nos primeiros anos do século XX (GROGAN, 2007).

No Brasil registra-se o uso do termo em São Paulo por volta do ano de 1929, no processo de implantação da atual Universidade Mackenzie na qual a atividade de referência era contemplada no âmbito do ensino. No Rio de Janeiro em 1938 a Biblioteca do Departamento Administrativo do Serviço Público (DASP) foi a primeira a contemplar a criação de um setor de referência. "Hoje em dia, o termo 'referência' tem um sentido mais amplo, pelo menos em Biblioteconomia, uma vez que o 'serviço de referência' abrange certo número de atividades e competências [...]" (ACCART, 2012, p. 3).

A partir desse século o termo serviço de referência passa a remeter a uma ação em que se encaminha o "sujeito leitor" a um determinado contexto informacional, tornando-se necessário a considerar na sociedade atual as mudanças sofridas com a intensificação do uso das tecnologias de informação e comunicação.

O impacto sofrido no serviço de referência acontece devido ao uso das novas tecnologias, impulsionando os sujeitos da era da informação a uma reordenação dos processos de busca, distribuição e produção dos fluxos de informação. Esse cenário acabou requerendo mudanças nas práticas e rotinas dos profissionais da informação. Ao apresentar uma nova paisagem, ocasionada pela explosão da informação, o progresso técnico e social passa a se fundamentar no poder criativo da linguagem e do raciocínio lógico previsto pelo currículo pleno, resultando não apenas numa compreensão da importância da comunicação verbal e escrita, mas também eletrônica e digital.

Le Coadic (2004) expõe que com o advento da eletrônica, da informática e do desenvolvimento da comunicação de informações à

4 O trabalho de Green, traduzido como "A conveniência de promover um relacionamento pessoal entre bibliotecários e leitores em bibliotecas populares", foi apresentado nessa conferência que resultou na fundação da "American Library Association" (ALA) (GROGAN, 2007). 
distância (telecomunicações), amplificou-se o armazenamento de enormes volumes de informações. Com isso, mudanças foram causadas com a chegada das novas tecnologias que acabaram contribuindo para o rompimento das barreiras ao criar um admirável mundo novo de produções, buscas e recuperação de uma infinidade de informações.

As transformações convergentes da sociedade da informação comumente são caracterizadas pelo uso das tecnologias de informação e comunicação no serviço de referência. Essa sociedade é constituída pelas tecnologias de informação que acabaram se transformando em um "[...] elemento constituinte e instituinte das nossas formas de ver e organizar o mundo" (ASSMANN, 2000, p. 10). Se para Assmann (2000) essa nova era é entendida como abreviação (discutível) de aspectos de uma sociedade em que há uma presença acentuada dessas tecnologias, para Castells (2011, p. 69) essa revolução é mais caracterizada pela aplicação da informação e geração de conhecimentos, assim como, pela criação "[...] de dispositivos de processamento/comunicação da informação, em um ciclo de realimentação cumulativo entre a inovação e seu uso" (CASTELLS, 2011, p. 69).

Essa nova paisagem emoldurada pelas tecnologias da escrita, informação e comunicação, ocasiona em mudanças na relação estabelecida entre bibliotecário e usuário no campo do serviço de referência, que na atualidade não remete apenas ao atendimento comumente oferecido em espaços presenciais. Tendo em vista que existem vários espaços tempos em que se pode buscar e recuperar uma mesma informação, o atendimento oferecido entre as paredes de uma biblioteca ou outra unidade de informação é ampliado no final do século $X X$.

No espaço virtual em pleno século $X X I$, o usuário passa a ter acesso a uma rede hipertextual. "Se tomarmos a palavra 'texto' em seu sentido mais amplo (que não exclui nem sons nem imagens), os hiperdocumentos também podem ser chamados de hipertextos" (LĖVY, 2010, p. 58). Essa rede, então, que está em constante construção e renegociação ao auxiliar processos de aprendizagens mais abertos, aparece como uma possibilidade de revitalizar o atendimento de referência em algumas unidades de informação, em bibliotecas, por exemplo, que ao possuir uma estrutura de acesso à Internet abre-se para inúmeras possibilidades de construção de projetos que auxiliem no processo de formação integral do sujeito.

As novas tecnologias permitem a aquisição de competências intelectuais, humanas e sociais, porém, o contrário também pode 
acontecer: o isolamento; a estagnação e sentimento de não pertencimento à sociedade em que vive. A multiplexação, amplificação e armazenamento de enormes volumes de informações ocorrem sem cessar e, às vezes, nos fazem duvidar da cordialidade da nova sociedade da informação (LE COADIC, 2004).

À vista disso, bibliotecário e usuário necessitam de competência em informação para trabalhar com processos de busca, recuperação e uso da informação considerando seus aspectos éticos e legais. A competência em informação pode ser definida como um conjunto de habilidades, conhecimentos e atitudes necessárias para o sujeito contemporâneo obter o sucesso de demandas sociais (e não apenas individuais) (BELLUZZO, 2007). Esse tipo de competência na sociedade contemporânea torna-se importante para a integração social do cidadão, na medida em que "O seu desenvolvimento capacita os indivíduos para o acesso, a seleção, a gestão e a avaliação da informação necessária à vida profissional, social e pessoal" (BELLUZZO; FERES, 2015, p. 8).

A competência no âmbito da informação no serviço de referência demanda a produção de conhecimentos e, principalmente, o monitoramento do uso efetivo das informações adquiridas, aspecto pouco investigado no campo dos estudos de usuários. Somente dessa forma o serviço de referência e informação passará a conceber no processo de busca e recuperação motivações, atitudes, emoções variadas e outros componentes sociais; já que, no processo de aquisição da competência em informação, "Atualmente, existe excesso de informação, e cada pessoa se encontra frente a uma variedade enorme de opções, o que faz com que seja necessário contar com estratégias que permitam selecionar a informações [...]" (BELLUZZO; FERES, 2015, p. 2).

A constatação de que esse tipo de competência requer uma combinação de conhecimentos (saber), habilidades (saber fazer) e atitudes (saber ser) no campo da informação, permite que o serviço de referência absorva os fazeres/as técnicas necessárias para desenvolver e a capacidade de buscar informações efetivas e saber usar equipamentos eletrônicos e ferramentas provenientes da era da Informação. Em se tratando da competência em informação daqueles que orientam e/ou que se utilizam do setor de informação e referência, principalmente virtual, destaca-se a competência necessária em termos de conhecimento para a implantação e viabilização desse importante setor, assim como, a necessidade de desenvolver a habilidade comunicativa daqueles que nele atendem 
presencialmente ou virtualmente. O fator humano ainda é relevante nessa frente de trabalho desenvolvida prevista pelo currículo e refletiva no campo da Biblioteconomia e Ciência da informação.

\section{CONSIDERAÇÕES FINAIS}

A partir das reflexões curriculares acerca da trajetória no ensino do curso de Biblioteconomia desde os currículos mínimos estabelecidos na área às Diretrizes Curriculares Nacionais para os cursos de Biblioteconomia, percebe-se uma perspectiva voltada para o serviço de referência às ações de competência em informação. A constatação de que esse tipo de competência requer uma combinação de conhecimentos (saber), habilidades (saber fazer) e atitudes (saber ser) no campo da informação, relacionando-se com a capacidade de buscar informações efetivas e saber usar equipamentos eletrônicos e ferramentas provenientes da era da Informação.

A área de recursos e serviços de informação contempla conteúdos referentes ao processo de mediação da informação entre os usuários e as fontes de informação, de modo que possam ser oferecidos serviços de recuperação e disseminação da informação para responder as necessidades dos usuários, bem como para desenvolver habilidades informacionais para o uso do universo informacional oferecido em espaços tempos híbridos (presenciais e virtuais).

Considera-se que competência informacional é um dos serviços inovadores que podem ser oferecidos nas instituições de ensino, agregando valor aos conhecimentos adquiridos pelos estudantes durantes o seu percurso escolar/acadêmico. Neste sentido, os cursos de Biblioteconomia devem possibilitar conteúdos curriculares que viabilizem aos futuros bibliotecários atuar na implementação de programas desta natureza em seus locais de atuação.

Perante 0 exposto, identifica-se que os profissionais bibliotecários devem ter conhecimento sobre a sua responsabilidade social, visando a cooperar para com a formação de cidadãos competentes no âmbito da informação, ao observar que devem trabalhar com as atividades que perpassam os processos de organização e tratamento da informação, estendendo-se aos serviços voltados aos usuários e aos programas de competência em informação que requer um aprendizado contínuo ao longo da vida. 
Em se tratando da competência em informação daqueles que orientam e utilizam do setor de referência e informação, presencial e virtual, devem desenvolver habilidades comunicativas ao considerar os diferentes repertórios culturais daqueles que atendem nesse setor. Portanto, destaca-se que o fator humano torna-se inteiramente relevante nessa frente de trabalho desenvolvido no campo da Biblioteconomia e Ciência da informação.

\section{REFERÊNCIAS}

ACCART, J. P. Serviço de referência: do presencial ao virtual. Briquet de Lemos: Brasília, 2012.

ASSMANN, H. A metamorfose do aprender na sociedade da informação. Ciência da Informação, Brasília, v. 29, n. 2, p. 7-15, maio/ago. 2000.

ASSOCIAÇÃO BRASILEIRA E EDUCAÇÃO EM CIÊNCIA DA INFORMAÇÃO (ABECIN). Atas das reuniões realizadas por área temática. In: ENCONTRO DE DOCENTES DE ESCOLAS DE BIBLIOTECONOMIA E CIÊNCIA DA INFORMAÇÃO DO MERCOSUL, 10, Belo Horizonte Anais... Belo Horizonte: UFMG, 2016.

BARITÉ-ROQUETA, M. G. IV Encuentro de directores y III de docentes de escuelas de bibliotecología y ciência de la información del MERCOSUR. In: VALENTIM, Marta Lígia Pomim; RODRIGUES, Mara Eliane Fonseca Rodrigues; ALMEIDA JÚNIOR, Oswaldo Francisco de (Coord.). Estudos sobre a formação do profissional da informação no Brasil e no Mercosul. Marília-SP: FUNDEPE, 2014. p. 61-94

BELLUZZO, R. C. B. Educação de usuários de bibliotecas universitárias: da conceituação e sistematização ao estabelecimento de diretrizes. 1989. 107 f. Dissertação (Mestrado em Ciências da Comunicação). Escola de Comunicação e Artes, Universidade de São Paulo, São Paulo, 1989.

BELLUZZO, R. C. B. Construção de mapas: desenvolvendo competências em informação e comunicação. 2. ed. Bauru, SP: Cá Entre Nós, 2007.

BELLUZZO, R. C. B.; FERES, G. G. Competência em informação, redes de conhecimento e as metas educativas para 2021: reflexões e inter-relações. In: BELLUZZO, Regina Célia Baptista; FERES, Glória Georges; VALETIM, Marta Lígia Pomim (Org.). Redes de conhecimento e competência em informação: interfaces da gestão, mediação e uso da informação. Rio de Janeiro: Interciência, 2015.

BRASIL. Lei 9.394, de 20 de dezembro de 1996. Estabelece as diretrizes e bases da educação nacional. Diário Oficial da União, Brasília, DF, 20 de dez. de 1996. Disponível em: <http://www.planalto.gov.br/ccivil_03/LEIS/I9394.htm> Acesso em: 15 set. 2017 
BRASIL. Lei N. 12.244, de 25 de maio de 2010. Dispõe sobre a universalização das bibliotecas nas instituições de ensino do país. Diário Oficial da União, República Federativa do Brasil: Imprensa Nacional, Brasília, DF, 2010b, Seção 1.

BRASIL. Ministério da Educação. Diretrizes Curriculares Nacionais dos cursos de Filosofia, História, Geografia, Serviço Social, Comunicação Social, Ciências Sociais, Letras, Biblioteconomia, Arquivologia e Museologia, 2001. Disponível em: <http://portal.mec.gov.br/cne/arquivos/pdf/CES0492.pdf.>. Acesso em: 12 set. 2017

CASTELLS, M. A Sociedade em Rede: a era da Informação: Economia, sociedade e Cultura. v. 1, São Paulo: Paz e Terra, 2011.

CASTRO, C. A. Histórico e evolução curricular na área de biblioteconomia no Brasil. In: VALENTIM, Marta Lígia. (Org.). Formação do profissional da Informação. São Paulo: Polis, 2002.

CERETTA-SORIA, M. G. IX Encuentro de directores y VIII de docentes de escuelas de bibliotecología y ciencia de la informaciín del MERCOSUR. In: ; RODRIGUES, Mara Eliane Fonseca Rodrigues; ALMEIDA JÚNIOR,

Oswaldo Francisco de (Coord.). Estudos sobre a formação do profissional da informação no Brasil e no Mercosul. Marília-SP: FUNDEPE, 2014. p. 177-201.

Ciência da Informação. Plano de ensino da disciplina Disseminação da Informação. Marília, 2017. 5p.

ESCOBAR-DE-MOREL, M. J. V Encuentro de directores y VI de docentes de escuelas de bibliotecología y ciencia de la informaciín del MERCOSUR. In: VALENTIM, Marta Lígia Pomim; RODRIGUES, Mara Eliane Fonseca Rodrigues; ALMEIDA JÚNIOR, Oswaldo Francisco de (Coord.). Estudos sobre a formação do profissional da informação no Brasil e no Mercosul. Marília-SP: FUNDEPE, 2014. p. 95-110

FREIRE, Isa. Maria. Janelas da cultura local: abrindo oportunidades para inclusão digital de comunidades. Ciência da Informação, Brasília, v. 35, n. 3, p. 227-235, set./ dez. 2006.

GROGAN, D. A prática do serviço de referência. Brasília: Briquet de Lemos, 2007.

GUIMARÃES, José Augusto Chaves. Estudos curriculares em biblioteconomia no Mercosul: reflexões sobre uma trajetória. In: VALENTIM, Marta Lígia. (Org.). Formação do profissional da informação. São Paulo: Polis, 2002. p. 49-88

GUIMARÃES, J. A. C. Moderno profissional da informação: elementos para sua formação no Brasil. Transinformação, Campinas, v. 9, n. 1, p. 124-137, jan./abr. 1997.

LE COADIC, Y. F. A ciência da informação. Brasília: Briquet de Lemos, 2004. 
LEITE, C. et al. Cenário e perspectiva da produção científica sobre competência em informação (Colnfo) no Brasil: estudo da produção no âmbito da ANCIB. Informação e Sociedade: Estudos, João Pessoa, v. 26, n. 3, p. 151-168, set./dez. 2016.

LEMOS, A. B. L. Estado atual da Biblioteconomia no Brasil e a questão da Ciência da Informação. Revista de Biblioteconomia de Brasília, v. 1, n. 1, jan./ jun. 1973.

LÉVY, P. Cibercultura. 3. ed. Tradução de Carlos Irineu da Costa. São Paulo: Ed. 34, 2010. 270 p.

MACEDO, N. D. Pesquisa em Ciência da Informação e biblioteconomia: questões de base; implicações na pós-graduação; análise temática. Ciência da Informação, v. 16, n. 2, p. 29-44, jul./dez. 1987.

MANGAS, S, F. A. Como planificar e gerir um serviço de referência. Biblios, n. 28, jun. 2007.

MATA, M. L. A inserção da competência informacional nos currículos dos cursos de Biblioteconomia no Brasil e nos cursos de Informação e Documentação na Espanha. 2014. 197 f. Tese (Doutorado em Ciência da Informação) - Universidade Estadual Paulista, Marília, 2014.

MOTA, F. R. L.; OLIVEIRA, M. Formação e atuação profissional. In: OLIVEIRA, Marlene. (Coord.). Ciência da Informação e Biblioteconomia: novos conteúdos e espaços de atuação. Belo Horizonte: UFMG, 2008. P. 97-110.

MUELLER, S. P. M. O ensino de biblioteconomia no Brasil. Ciência da Informação, Brasília, v. 14, n. 1, p. 3-15, jan./ jun. 1985.

NOBREGA, N. G. da. A caverna, o monstro e o medo. RJ: Casa da Leitura, 1995.

OLIVEIRA, M.; CARVALHO, G. F.; SOUZA, G. T. Trajetória histórica do ensino de biblioteconomia no Brasil. Informação \& Sociedade: Est., João Pessoa, v. 19, n. 3, p. 13-24, set./dez. 2009.

OTA, M. E. C. Educação de usuários em bibliotecas universitárias brasileiras: revisão de literatura nacional. Revista Brasileira de Biblioteconomia e Documentação, São Paulo, v. 23, n. 1/4, p. 58-77, jan./dez., 1990.

SANTOS, J. P. O moderno profissional da informação: o bibliotecário e seu perfil face aos novos tempos. Informação e Informação, Londrina, v. 1, n. 1, p. 5-13, jan./ jun. 1996.

SOUZA, F. C. A ABEBD e o currículo de bacharelado em biblioteconomia no Brasil, de 1967 a 2000. Informação \& Sociedade, v. 21, p. 203-212, 2011.

SOUZA, F. C. $O$ ensino da biblioteconomia no contexto brasileiro: século XX. Florianópolis: UFSC, 2009.

UNIVERSIDADE ESTADUAL PAULISTA. (Departamento de Ciência da Informação/ Conselho de Curso de Biblioteconomia. Projeto político pedagógico do curso de Biblioteconomia. Marília: UNESP, 2012 
VALENTIM, M. L. P. Assumindo um novo paradigma na biblioteconomia. Informação \& Informação, Londrina, v. 00, n. 0, p. 2-6, 1995.

VALENTIM, M. L. P. O moderno profissional da informação: formação e perspectiva profissional. Encontros Bibli: Revista Eletrônica de Biblioteconomia, Florianópolis, n. 9, p. 16-28, 2000.

VALENTIM, M. L. P. VI Encontro de diretores e V encontro de docentes de escolas de biblioteconomia e ciência da informação do MERCOSUL. In: ; RODRIGUES, Mara Eliane Fonseca Rodrigues; ALMEIDA JÚNIOR, Oswaldo Francisco de (Coord.). Estudos sobre a formação do profissional da informação no Brasil e no Mercosul. Marília-SP: FUNDEPE, 2014. p. 111-138. 